\title{
O Impacto da Justiça Organizacional sobre o Bem-Estar Laboral: Um Estudo com Trabalhadores do Varejo
}

\author{
The Impact of Organizational Justice on Employee Well-Being: A Study with
} Retail Workers

» Verônica da Costa MASAGÃO (Universidade Salgado de Oliveira, Brasil)

» Maria Cristina FERREIRA ${ }^{1}$ (Universidade Salgado de Oliveira, Brasil)

Resumo

O presente estudo teve como objetivo geral investigar o valor preditivo das percepções de justiça organizacional (distributiva, processual, informacional e interpessoal) sobre o bem-estar laboral, expresso por meio da satisfação no trabalho e dos afetos positivos dirigidos a ele. A amostra foi composta por 454 profissionais da área do comércio varejista de Niterói, São Gonçalo e Rio de Janeiro, que responderam a uma escala de satisfação no trabalho, a uma escala de afetos positivos dirigidos ao trabalho e uma escala de percepção de justiça organizacional. Os dados obtidos evidenciaram que: (1) as percepções de justiça processual, interpessoal e distributiva predizem positivamente a satisfação no trabalho; (2) as percepções de justiça distributiva, processual, informacional e interpessoal predizem positivamente os afetos positivos dirigidos ao trabalho; (3) entre as percepções de justiça organizacional, as percepções de justiça processual são as que melhor predizem a satisfação no trabalho; (4) quanto maior a idade, maior a satisfação no trabalho. Tais resultados são discutidos à luz dos modelos teóricos e estudos empíricos que deram suporte à pesquisa.

Palavras-chave:

justiça organizacional; satisfação no trabalho; afetos positivos dirigidos ao trabalho; comércio varejista.

The intent of this study was to investigate the predictive value of organizational justice perceptions (distributive, Abstract procedural, informational, and interpersonal) on worker well-being, expressed by job satisfaction and by positive affects toward work. The sample was composed of 454 retail area professionals from Niterói, São Gonçalo, and Rio de Janeiro. They responded to a scale of job satisfaction, a scale of positive affects toward work, and a scale of organizational justice perceptions. The results showed that: (1) the perceptions of procedural, interpersonal, and distributive justice were positive predictors of job satisfaction; (2) the perceptions of distributive, procedural, informational and interpersonal justice were positive predictors of positive affects toward work; (3) amongst the four organizational justice perceptions, procedural justice perceptions were the best predictor of job satisfaction; (4) the higher the age, the greater the job satisfaction. Such results are discussed from the perspective of the theoretical models and empirical studies supporting the research.

Keywords:

organizational justice perceptions; job satisfaction; positive affects toward work; retailing.

Resumen El presente estudio tuvo como objetivo general investigar el valor predictivo de las percepciones de justicia organizacional (distributiva, procesal, informacional e interpersonal) sobre el bienestar laboral, expresado por medio de la satisfacción en el trabajo y de los afectos positivos dirigidos al trabajo. La muestra fue compuesta por 454 profesionales del área de ventas al por menor de Niterói, São Gonçalo y Rio de Janeiro, que respondieron a una escala de satisfacción con el trabajo, una escala de afectos positivos dirigidos al trabajo y una escala de percepción de la justicia organizacional. Los datos mostraron que: (1) las percepciones de justicia procesal, interpersonal y distributiva predicen positivamente la satisfacción con el trabajo; (2) las

1 Endereço para contato:Maria Cristina Ferreira - Rua Marquês de Valença, 80 Apto. 602 - Tijuca, Rio de Janeiro-RJ - CEP: 20550-030

- Telefone: 21- 8898-9207 / Fax: 21-2565-7903. E-mail: mcris@centroin.com.br 
percepciones de justicia distributiva, procesal, informacional e interpersonal predicen positivamente los afectos positivos dirigidos al trabajo; (3) entre las percepciones de justicia organizacional, las percepciones de justicia procesal, son las que mejor predicen la satisfacción con el trabajo; (4) cuanto mayor la edad, mayor la satisfacción con el trabajo. Tales resultados, son discutidos a la luz de dos modelos teóricos y estudios empíricos que dieron soporte a la investigación.

Palabras-clave:

justicia organizacional; satisfacción con el trabajo; afectos positivos dirigidos al trabajo; ventas al por menor. 
$\mathrm{O}$ mundo vem passando por uma série de transformações, que se refletem não apenas na sociedade em geral, mas também nos indivíduos e nas organizações de trabalho. Globalização dos mercados, grandes avanços tecnológicos, flexibilização das relações de trabalho e aumento da competitividade são algumas transformações assistidas nas últimas décadas (Mattar, 2011).

No que tange às organizações e aos processos de trabalho, as mudanças mencionadas acarretaram profundas modificações nas rotinas de trabalho e no cotidiano dos trabalhadores. Na esteira de tais mudanças, o trabalho de qualidade e o uso de tecnologias constantemente atualizadas tornaram-se exigência fundamental do mundo globalizado. Todas essas transformações fizeram-se acompanhar por um interesse cada vez maior dos estudiosos pela saúde e bem-estar do trabalhador. O objetivo é prevenir as doenças que se desenvolvem no local de trabalho, de modo a se obter um ambiente saudável que garanta a qualidade de vida do trabalhador (Siqueira \& Padovam, 2008).

Durante longo tempo, porém, o foco das investigações nessa área foi o trabalho visto como uma fonte de desgaste e sofrimento para o trabalhador. Nesse sentido, grandes quantias foram gastas em pesquisas sobre os danos provocados pelos acidentes de trabalho. Paralelamente, o estresse laboral passou a ser visto como um problema de ordem pública, em função das sérias consequências que acarretava para os indivíduos, organizações e sociedade (Calvetti, Muller, \& Nunes, 2007).

No entanto, com o advento da Psicologia Positiva, os estudiosos passaram a dar mais atenção ao trabalho enquanto fonte de prazer, saúde e satisfação, em função de atender às necessidades profissionais do indivíduo. Em outras palavras, há maior preocupação com a qualidade de vida do empregado e a prevenção de doenças (Paludo \& Koller, 2007).

Acompanhando esse novo contexto, a última década foi marcada por um volume crescente de pesquisas destinadas a investigar os principais fatores organizacionais e individuais que concorrem para o bem-estar laboral. Entre eles, merece destaque a justiça organizacional, que se refere às percepções e reações de justiça vivenciadas pelos empregados em relação à organização em que trabalham (Assmar, Ferreira \& Souto, 2005). $\mathrm{O}$ referido construto tem se revelado um preditor de diferentes atitudes e comportamentos organizacionais, tais como o comprometimento organizacional, a satisfação no trabalho e a cidadania organizacional.

No entanto, o exame da literatura brasileira e estrangeira veiculada nas bases de dados Scielo, Pepsic e Psychinfo (com as palavras-chave justiça organizacional, bem-estar no trabalho, bem-estar laboral, bem-estar profissional, organizational justice, well-being at work, job well-being, employee well-being) evidencia que apenas nos últimos anos os estudiosos do comportamento organizacional passaram a se dedicar à investigação das implicações da justiça organizacional para o bem-estar do trabalhador. Todavia, as investigações brasileiras destinadas à análise dos efeitos da justiça organizacional sobre o bem-estar do trabalhador ainda são incipientes, ainda que já estejam disponíveis na literatura nacional diversos estudos com foco nas percepções de justiça organizacional (Ferreira et al., 2006; Fiuza, 2010; Mendonça \& Mendes, 2005; Rego \& Souto, 2004; Souza \& Mendonça, 2009). Tal cenário evidencia, portanto, a necessidade de pesquisas adicionais que possam contribuir para a maior compreensão do assunto. Em face dessas considerações, o presente trabalho teve como objetivo geral verificar a influência das percepções de quatro dimensões de justiça organizacional (distributiva, processual, interpessoal e informacional) sobre o bem-estar laboral (satisfação no trabalho e afetos positivos dirigidos ao trabalho) de trabalhadores do setor varejista de vestuário.

A opção pelo grupo ocupacional referido deu-se em função de o setor de tecidos, vestuário e calçados situar-se entre um dos principais setores varejistas do país na atualidade, sendo responsável por uma grande quantidade de empregos formais e informais (Mattar, 2011). Nesse sentido, dados do Instituto Brasileiro de Geografia e Estatística (IBGE, 2014) revelam que o setor, em novembro de 2014, foi responsável pela 4a contribuição à taxa global do varejo, com aumento de 1,6 \% no volume de vendas em novembro, em relação a igual mês de 2013. No Estado do Rio de Janeiro, especificamente, esse segmento contribuiu com 1,2 \% do volume total de vendas no mês, e com 3,2\% do volume total de vendas anual. Contudo, os estudos brasileiros sobre bem-estar no trabalho têm privilegiado os grupos ocupacionais pertencentes aos setores da saúde (Gouveia, Lins, Lima, Freires, \& Gomes, 2009; Ruviaro \& Bardagi, 2010), da educação (Rocha Sobrinho \& Porto, 2012; Traldi \& Demo, 2012) e da indústria (Horta, Demo, \& Roure, 2012), bem como ao setor público (Paschoal, Torres, \& Porto, 2010). Justificam-se, dessa forma, investigações adicionais que sejam capazes de contribuir para a elucidação do modo pelo qual as percepções de justiça organizacional impactam o bem-estar dos trabalhadores do setor varejista de vestuário. 


\section{Bem-estar no trabalho}

A expressão bem-estar no trabalho vem sendo definida de várias formas, o que evidencia a falta de consenso acerca dos limites conceituais desse construto. Nesse sentido, Siqueira e Padovam (2008) assinalam que cada autor aborda o bem-estar no trabalho de uma maneira diferente, associando-o, assim, a fenômenos muito diversos, como a satisfação no trabalho, o burnout, o estresse ocupacional, a segurança no trabalho e o estilo gerencial, entre outros.

Um dos primeiros estudiosos a se deter no estudo do bem-estar específico ao contexto do trabalho foi Warr (2004). De acordo com esse autor, o bem-estar afetivo pode ser visto como um componente da saúde mental no trabalho, que inclui, ainda, outras dimensões, tais como a autoestima positiva, a competência, a necessidade de autorrealização, a autonomia e o funcionamento integrado. No entanto, Warr (2004) dedica-se mais especificamente à análise de bem-estar afetivo no trabalho e seus antecedentes.

$\mathrm{Na}$ caracterização dos componentes do bem-estar no trabalho, Warr (1987) parte de dois eixos iniciais: o prazer versus o desprazer e a excitação versus o relaxamento. A combinação dos dois dará origem a um eixo de entusiasmo (excitação versus prazer), que se opõe à depressão (relaxamento versus desprazer), e a um eixo de ansiedade (excitação versus desprazer), que se opõe ao conforto (relaxamento versus prazer). $\mathrm{O}$ eixo de excitação versus relaxamento, por si só, não se configura como uma dimensão do bem-estar positivo, sendo usado apenas para formar os demais. Desse modo, para Warr (2004), o bem-estar desdobra-se em três eixos bipolares: o prazer versus o desprazer, a ansiedade versus o conforto e a depressão versus o entusiasmo. $\mathrm{O}$ presente trabalho deteve-se no estudo de dois indicadores afetivos do bem-estar, quais sejam a satisfação no trabalho, que corresponde à dimensão de prazer versus desprazer do modelo de Warr (2004), e os afetos positivos dirigidos ao trabalho, que se associam aos polos positivos das dimensões de ansiedade versus conforto e de depressão versus entusiasmo.

A satisfação no trabalho é por vezes considerada como um estado puramente afetivo e, por vezes como um fenômeno cognitivo-afetivo (Weiss, 2002). Desse modo, Locke (1976) afirma que a satisfação no trabalho consiste em um estado emocional positivo, resultante de avaliações do trabalhador sobre o próprio trabalho. Spector (1997), no entanto, leva em consideração dois elementos para definir a satisfação no trabalho: o fator cognitivo, isto é, o que a pessoa pensa sobre seu trabalho, e o elemento afetivo, que se relaciona ao que ela sente sobre o seu trabalho diário. Já os afetos positivos sobre o trabalho dizem respeito aos vínculos subjetivos e positivos dos indivíduos com sua organização, manifestando-se por meio de emoções, sentimentos e humores positivos (Forgas, 2001; Weiss \& Cronpazano, 1996).

\section{Justiça organizacional}

A justiça organizacional diz respeito à psicologia da justiça que se aplica ao ambiente de trabalho, ou seja, às percepções e reações de justiça ou injustiça vivenciadas pelos empregados em relação à organização em que trabalham (Assmar et al., 2005). Desse modo, um evento é considerado justo ou injusto na medida em que o empregado acredita que a situação experienciada por ele ocorreu dessa forma.

As investigações sobre justiça organizacional têm procurado identificar seus principais antecedentes e consequentes, bem como suas dimensões. Com relação ao último aspecto, a justiça organizacional costuma ser considerada um fenômeno multidimensional que, na opinião de vários autores (Assmar et al., 2005; Gilliland \& Chan, 2001; Walster, Berscheid, \& Walster, 1973), desdobra-se em pelo menos três dimensões: justiça distributiva, justiça procedimental ou processual e justiça interacional.

A justiça distributiva diz respeito à justiça dos resultados alcançados, ao modo como foi feita a distribuição dos recursos positivos ou negativos, tais como salários, promoções, serviços, etc. A justiça processual associa-se ao processo pelo qual os resultados são atribuídos. O princípio subjacente é o de que os procedimentos são elaborados e criados com a intenção de simplificar, regular e minimizar os conflitos intergrupais (Mendonça \& Mendes, 2005). A justiça interacional, por sua vez, relaciona-se ao modo pelo qual os procedimentos são colocados em prática (Cropanzano \& Discorfano, 2009).

Alguns autores (Cropanzano \& Greenberg, 1997; Tyler \& Lind, 1992) não fazem distinção entre justiça interacional e justiça processual, com base no argumento de que essas duas modalidades têm consequências similares. Para eles, então, a justiça interacional constitui-se como uma extensão da justiça processual. Outros autores (Bies \& Moag, 1986; Greenberg, 1993), porém, consideram a justiça interacional uma dimensão 
distinta da justiça processual, que tem como prioridade a qualidade do tratamento recebido pelas pessoas no desenvolvimento dos procedimentos organizacionais.

Os componentes sociais presentes na justiça interpessoal ainda podem ser divididos em duas outras dimensões: justiça interpessoal e justiça informacional. A justiça interpessoal associa-se à sensibilidade social, isto é, ao modo pelo qual o gestor trata o colaborador atingido pelas decisões tomadas na organização, enquanto a justiça informacional diz respeito ao recebimento de informações sobre as decisões tomadas (Assmar et al., 2005). Este modelo tetradimensional de justiça foi o adotado como referencial teórico do presente trabalho, no que tange às percepções de justiça organizacional.

\section{Justiça organizacional e bem-estar laboral}

Os estudos sobre as percepções de justiça organizacional e a satisfação no trabalho têm evidenciado que as percepções de justiça distributiva associam-se positivamente à satisfação no trabalho (Andrews, Baker, \& Hunt, 2008; Clay-Warner, Reynolds, \& Roman, 2005; Fields, Pang, \& Chiu, 2000; Harvey \& Haines III, 2005; Lawson, Noblet, \& Rodwell, 2009; Suliman, 2007), o mesmo ocorrendo com as percepções de justiça processual (Andrews et al., 2008; Clay-Warner et al., 2005; Fields et al., 2000; Harvey \& Haines III, 2005; Lawson et al., 2009; Suliman, 2007), de justiça interacional (Andrews et al., 2008; Suliman, 2007), de justiça interpessoal (Lawson et al., 2009) e de justiça informacional (Lawson et al., 2009). Contudo, quando se comparam as percepções de justiça distributiva e de justiça processual, esta última tem se mostrado melhor preditora do bem-estar no trabalho (Gilliland \& Chan, 2001). Além disso, quando as percepções de justiça distributiva, processual e interacional são comparadas, são as percepções de justiça processual e interacional (interpessoal e/ou informacional) que se destacam como melhores preditoras do bem-estar laboral (Cropanzano \& Discorfano, 2009).

Em síntese, os estudos sobre as relações das percepções de justiça organizacional com a satisfação no trabalho têm aparecido com relativa frequência no cenário internacional. No Brasil, porém, isso não ocorre, apesar de já haver considerável literatura brasileira disponível sobre as percepções de justiça organizacional, conforme apontado na introdução do presente trabalho. Por outro lado, não foi encontrado nenhum estudo nas bases de dados pesquisadas (Psychinfo, Scielo e Pepsic) com foco nas relações entre as percepções de justiça organizacional e os afetos positivos dirigidos ao trabalho. Justifica-se, portanto, a realização de investigações que possam elucidar o papel desempenhado pelas diversas facetas da justiça no bem-estar de trabalhadores brasileiros, expresso por meio da satisfação e dos afetos dirigidos ao trabalho.

Fundamentando-se em tais considerações, o objetivo do presente trabalho foi investigar a influência das percepções das quatro dimensões da justiça organizacional (distributiva, processual, interpessoal e informacional) sobre o bem-estar laboral, avaliado por meio da satisfação e dos afetos positivos dirigidos ao trabalho, em trabalhadores do comércio varejista do setor de vestuário. Para tanto, foram formuladas as hipóteses que seguem, com o apoio dos estudos empíricos revistos. Cumpre registrar, porém, que as hipóteses compreendendo os afetos positivos dirigidos ao trabalho como variáveis dependentes foram formuladas em caráter exploratório e com base apenas na semelhança conceitual desse construto com a satisfação no trabalho, em função de não terem sido encontrados estudos anteriores com esse foco.

H 1 - As percepçôes de justiça distributiva, processual, informacional e interpessoal predizem positivamente a satisfação no trabalho.

H2 - As percepçôes de justiça distributiva, processual, informacional e interpessoal predizem positivamente os afetos positivos dirigidos ao trabalho.

H3 - Entre as percep̧̧ôes das quatro dimensões de justiça, a que melhor prediz a satisfação no trabalho é a justiça processual.

H 4 - Entre as percepções das quatro dimensões de justiça, a que melhor prediz os afetos positivos dirigidos ao trabalho é a justiça processual.

\section{MÉTODO}

\section{Participantes}

Participaram da pesquisa 454 profissionais do setor de vestuário do comércio varejista, distribuídos em 20 lojas das cidades de Niterói, São Gonçalo e Rio de Janeiro. Cumpre registrar, porém, que a amostra foi 
de conveniência. Nesse sentido, não foram levantadas informações acerca do quantitativo total da população investigada que permitissem cálculos mais precisos acerca da representatividade da amostra. Do total de participantes, $58,4 \%(\mathrm{n}=265)$ pertenciam ao sexo feminino e suas idades variavam de 18 a 57 anos $(M=30,21$; $D P=8,36)$. Com relação à escolaridade, grande parte dos respondentes $(78,0 \%, \mathrm{n}=354)$ possuía o ensino médio ou o ensino superior incompleto. $\mathrm{O}$ tempo de trabalho desses indivíduos nas organizações pesquisadas variou de 1 a 23 anos (média = 4,34; desvio padrão = 4,30), enquanto seu tempo total de serviço variou de 1 a 36 anos (média $=9,65$; desvio padrão $=7,94$ ). No que tange ao cargo exercido pelos participantes da amostra, $57,5 \%(\mathrm{n}=261)$ eram funcionários da área administrativa operacional e 20\% $(\mathrm{n}=91)$ pertenciam à área de vendas, enquanto os $22,5 \%(\mathrm{n}=102)$ restantes exerciam algum tipo de cargo de chefia (diretor, gerente sênior, gerente médio ou supervisor).

\section{Instrumentos}

$\mathrm{Na}$ avaliação da satisfação no trabalho, foi utilizada a Escala de Satisfação Geral no Trabalho (Silva \& Ferreira, 2009), que é unifatorial e composta por cinco itens a serem respondidos em escalas de cinco pontos, variando de concordo fortemente (5) a discordo fortemente (1), de acordo com o grau de satisfação do respondente em relação a seu trabalho. No estudo de validação original, o coeficiente de consistência interna dessa escala, calculado pelo coeficiente Alfa de Cronbach, foi igual a 0,80. Na pesquisa atual, o coeficiente Alfa de Cronbach dessa escala foi de 0,90.

Os afetos positivos dirigidos ao trabalho foram avaliados pela versão resumida da subescala de afetos positivos da Escala de Afetos no Trabalho (ESAFE), de autoria de Ferreira, Silva, Fernandes e Pacheco (2008), na qual constam 10 itens, a serem respondidos em escalas de cinco pontos, variando de nunca (1) a sempre (5), de acordo com a frequência de emoções vivenciadas no último mês em relação ao trabalho. $\mathrm{O}$ índice de consistência interna da escala, no estudo original, calculado pelo Alfa de Cronbach, foi de 0,93. Na presente pesquisa, o coeficiente Alfa de Cronbach dessa escala foi igual a 0,95.

As percepções de justiça organizacional foram avaliadas pela Escala de Percepção de Justiça de Colquitt (2001), composta por 20 itens, em formato de cinco pontos, variando de "nunca" a "sempre", distribuídos igualmente entre quatro dimensões: justiça distributiva, justiça processual, justiça interpessoal e justiça informacional. A referida escala foi validada em amostras brasileiras por meio do estudo de Assmar et al. (2002), no qual se verificou sua validade de construto, mediante análises fatoriais exploratórias em que os itens reproduziram de forma integral a estrutura prevista pela teoria, bem como seus índices de consistência interna, que variaram de 0,82 a 0,89. Na pesquisa atual, os coeficientes Alfa de Cronbach foram iguais a 0,86 (justiça processual), 0,84 (justiça distributiva) e 0,85 (justiça interacional e justiça informacional). Foram incluídas ainda, no instrumento de coleta de dados, algumas perguntas destinadas à coleta de informações sociodemográficas sobre os participantes e o termo de consentimento livre e esclarecido.

\section{Procedimento}

Inicialmente, o projeto foi submetido e aprovado pelo Comitê de Ética em Pesquisa da instituição da qual as autoras fazem parte. Em seguida, foram contatados diretamente os principais responsáveis pelas diferentes lojas visitadas, os quais autorizaram a realização da pesquisa com os vendedores, supervisores, gerentes e diretores de cada uma delas. $\mathrm{Na}$ aplicação dos instrumentos aos empregados administrativos, os questionários foram enviados diretamente aos supervisores e gerentes, que se encarregaram de distribuir os questionários a seus funcionários em envelopes lacrados e devolvê-los preenchidos e devidamente lacrados. Alguns questionários foram também enviados por e-mail e devolvidos da mesma forma após seu preenchimento. A todos os participantes foi assegurado o anonimato.

\section{RESULTADOS}

As informações provenientes dos questionários respondidos originaram um banco de dados analisado com a utilização do programa SPSS (Statitical Package for the Social Science), em sua versão 17.0. Em seguida, foram calculadas as médias e o desvio padrão de cada uma das escalas, bem como os coeficientes de correlação entre elas (Tabela 1). Posteriormente, examinou-se o atendimento aos pressupostos para a realização das análises de regressão, verificando-se que todos eles (normalidade, homocedasticidade, linearidade, ausência 
de multicolinearidade e ausência de outliers uni e multivariados) foram atendidos, razão pela qual não houve necessidade de transformação de nenhuma das variáveis do estudo.

TABELA 1. Correlação Entre as Percepções de Justiça Organizacional e o Bem-estar Aboral

\begin{tabular}{|c|c|c|c|c|c|c|c|c|}
\hline Variáveis & Média & DP & 1 & 2 & 3 & 4 & 5 & 6 \\
\hline 1 & 3,52 & 0,78 & - & & & & & \\
\hline 2 & 3,73 & 0,82 & $0,60^{* *}$ & --- & & & & \\
\hline 3 & 3,75 & 0,86 & $0,52^{* *}$ & $0,62^{* *}$ & --- & & & \\
\hline 4 & 3,65 & 0,85 & $0,59^{* *}$ & $0,59^{\star *}$ & $0,73^{\star *}$ & --- & & \\
\hline 5 & 3,28 & 0,91 & $0,50^{* *}$ & $0,49^{* *}$ & $0,50^{\star \star}$ & 0,50 ** & --- & \\
\hline 6 & 3,72 & 0,83 & $0,51^{* *}$ & $0,52^{\star *}$ & $0,56^{\star *}$ & $0,57^{\star *}$ & $0,71^{* *}$ & --- \\
\hline
\end{tabular}

${ }^{*} p<0,05{ }^{* *} p<0,01$

Nota: 1. Justiça processual; 2. Justiça distributiva; 3. Justiça interpessoal; 4. Justiça informacional; 5. Satisfação no trabalho; 6 . Afetos positivos dirigidos ao trabalho.

Com o objetivo de verificar o poder preditivo das percepções de justiça distributiva, processual, interpessoal e informacional na satisfação no trabalho e nos afetos positivos dirigidos ao trabalho, foram realizadas duas análises de regressão múltipla linear hierárquica diferentes. Ambas incluíram as variáveis sociodemográficas sexo (como variável dummy, com sexo feminino $=1$ e sexo masculino $=0$ ), idade, tempo de emprego atual e tempo total de serviço como variáveis de controle, porque elas ocupam tradicionalmente essa condição nos estudos da área. No segundo modelo, foram acrescentadas as percepções sobre as quatro dimensões de justiça organizacional.

A análise de regressão múltipla linear hierárquica tendo como variável critério a satisfação no trabalho (Tabela 2) revelou que o primeiro modelo foi significativo e explicou $6 \%$ da satisfação $\left(R^{2}=0,06 ; F_{(4,438)}=7,53\right.$; $p<0,001)$. Contudo, nenhuma das variáveis atingiu significância estatística. $\mathrm{O}$ acréscimo das percepções de justiça ao modelo representou um aumento de $30 \%$ da variância explicada $\left(R^{2}{ }_{\Delta}=0,30 ; F_{(4,434)}=53,31 ; p<0,01\right)$. Nele, as percepções de justiça processual destacaram-se como o melhor preditor positivo da variável critério, seguidas pela idade, percepções de justiça interpessoal e percepções de justiça distributiva.

Em síntese, o modelo final retido contribuiu para explicar 36\% da variância da satisfação no trabalho $\left(R^{2}=\right.$ 0,$\left.36 ; F_{(8,434)}=32,22 ; p<0,001\right)$ e indicou que as pessoas que avaliam como mais justos os procedimentos de tomada de decisão, os resultados auferidos e o modo como são tratados na implementação desses procedimentos costumam se mostrar mais satisfeitas com o trabalho. Foi verificado, ainda, que as pessoas mais velhas tendem a apresentar maior satisfação no trabalho.

TABELA 2. Resultado das Análises de Regressão do Bem-estar Laboral Sobre as Percepções de Justiça Organizacional

\begin{tabular}{|c|c|c|c|c|}
\hline \multirow{3}{*}{ Variáveis } & \multicolumn{2}{|c|}{ Satisfação no trabalho } & \multicolumn{2}{|c|}{ Afetos positivos dirigidos ao trabalho } \\
\hline & Modelo 1 & Modelo 2 & Modelo 1 & Modelo 2 \\
\hline & $\beta$ & $\beta$ & $\beta$ & $\beta$ \\
\hline Idade & 0,09 & $0,20^{*}$ & $-0,17$ & $-0,02$ \\
\hline Tempo de emprego atual & $-0,04$ & 0,07 & $-0,02$ & $-0,06$ \\
\hline Tempo total de serviço & 0,19 & $-0,03$ & $0,36^{\star \star}$ & 0,10 \\
\hline Sexo & $-0,01$ & 0,04 & $-0,05$ & $-0,09^{*}$ \\
\hline Percepções da justiça processual & & $0,23^{\star \star *}$ & & $0,19^{\star *}$ \\
\hline Percepções da justiça distributiva & & $0,16^{\star \star}$ & & $0,13^{\star}$ \\
\hline Percepções da justiça interpessoal & & $0,18^{* *}$ & & $0,22^{* * *}$ \\
\hline Percepções da justiça informacional & & $-0,12$ & & $0,22^{\star \star \star}$ \\
\hline
\end{tabular}

${ }^{*} p<0,05^{\star *} p<0,01{ }^{* * *} p<0,001$

A análise de regressão múltipla linear hierárquica tendo como variável critério os afetos positivos dirigidos ao trabalho (Tabela 2) revelou que o primeiro modelo foi significativo e explicou $5 \%$ da variável critério $\left(R^{2}\right.$ $\left.=0,05 ; F_{(4,438)}=6,16 ; p<0,001\right)$. Contudo, a única variável que se destacou como preditora foi o tempo total de serviço. O acréscimo das percepções de justiça ao modelo representou um aumento de $38 \%$ da variância explicada $\left(R_{\Delta}^{2}=0,38 ; F_{(4,434)}=73,95 ; p<0,001\right)$. Nele, as percepções de justiça interpessoal e de justiça informacional destacaram-se como os maiores preditores da variável critério, seguidas pelas percepções de justiça processual, percepções de justiça distributiva e, por último, pelo sexo. No que tange ao sexo, porém, a 
comparação entre os dois grupos evidenciou a inexistência de diferenças significativas entre eles $(t=1,47, p>$ 0,05), razão pela qual o resultado obtido na regressão foi interpretado como um efeito supressivo do sexo em relação ao tempo total de serviço, que deixou de ter significância estatística no segundo modelo.

Dessa forma, o modelo final retido contribuiu para explicar $43 \%$ da variância dos afetos positivos dirigidos ao trabalho $\left(R^{2}=0,43 ; F_{(8,434)}=42,11 ; p<0,001\right)$ e revelou que as pessoas que percebem como mais justos os procedimentos de tomada de decisão, os resultados auferidos e o modo como são tratados, tanto na implementação quanto na comunicação desses procedimentos, costumam demonstrar mais afetos positivos em direção ao seu trabalho.

\section{DISCUSSÃO}

A presente pesquisa teve como objetivo geral investigar o impacto das percepções de justiça organizacional (distributiva, processual, interpessoal e informacional) sobre o bem-estar laboral (satisfação no trabalho e afetos positivos dirigidos ao trabalho) de trabalhadores do setor varejista de vestuário. No que diz respeito à satisfação no trabalho, a análise de regressão múltipla hierárquica evidenciou que as percepções de justiça processual, seguidas pelas de justiça interpessoal e de justiça distributiva, constituíram-se como preditoras positivas e significativas dessa variável critério. Tais resultados confirmam parcialmente a Hipótese 1, segundo a qual as percepções das quatro dimensões de justiça (distributiva, processual, interpessoal e informacional) prediziam positivamente a satisfação no trabalho.

Tais dados mostram-se congruentes com os diversos estudos anteriores que também têm demonstrado que as percepções de justiça processual (Andrews et al., 2008; Clay-Warner et al., 2005; Fields et al., 2000; Harvey \& Haines III, 2005; Lawson et al., 2009; Suliman, 2007), assim como as percepções de justiça interpessoal (Lawson et al., 2009) e de justiça distributiva (Andrews et al., 2008; Clay-Warner et al., 2005; Fields et al., 2000; Harvey \& Haines III, 2005; Lawson et al., 2009; Suliman, 2007) caracterizam-se como preditoras positivas da satisfação no trabalho. Por outro lado, eles divergem das pesquisas (Lawson et al., 2009) que têm demonstrado o papel preditor positivo desempenhado pelas percepções de justiça informacional na satisfação no trabalho.

No que se refere aos afetos positivos dirigidos ao trabalho, a análise de regressão múltipla hierárquica evidenciou que todas as percepções de justiça organizacional (distributiva, processual, interpessoal e informacional) constituíram-se como preditoras positivas e significativas dessa variável critério. Desse modo, a Hipótese 2, que preconizava que as quatro dimensões de justiça iriam predizer positivamente os afetos positivos dirigidos ao trabalho, foi totalmente confirmada.

Os resultados obtidos podem ser interpretados à luz da teoria da troca social, segundo a qual um tratamento justo por parte da organização configura-se como uma troca social à qual o empregado responde apresentando comportamentos organizacionais positivos (Cropanzano \& Discorfano, 2009). Outra interpretação possível advém do modelo de Warr (1987), que preconiza que o fato de o empregado receber feedback em relação a seu comportamento na organização constitui-se em um antecedente positivo do bem-estar laboral. Considerandose que as percepções de justiça interacional envolvem o tratamento justo por parte dos supervisores, o que muito provavelmente envolve o recebimento de feedbacks, seria de se esperar, portanto, que essas percepções impactassem positivamente o bem-estar laboral, como de fato ocorreu.

De acordo com a Hipótese 3, entre as quatro percepções de justiça a que melhor predizia a satisfação no trabalho era a justiça processual, o que se confirmou na presente pesquisa, na medida em que tal dimensão foi a que obteve o beta $(\beta)$ mais alto entre as três dimensões de justiça positiva e significativamente associadas à satisfação no trabalho.Tais dados corroboram, assim, as asserções de Gilliland e Chan (2001) e de Cropanzano e Discorfano (2009), acerca da primazia das percepções de justiça processual sobre as percepções dos demais tipos de justiça, no que tange a seus efeitos sobre o bem-estar laboral.

Segundo o modelo de controle (Cropanzano \& Discorfano, 2009), o envolvimento dos funcionários nos processos de tomada de decisão permite-lhes apresentar seus próprios argumentos e assumir parte da responsabilidade nas decisões tomadas. Tal participação ou controle da situação leva-os a avaliar mais favoravelmente a justiça processual. Assim, é provável que a avaliação mais favorável da justiça processual, em comparação às demais, tenha decorrido do fato de os empregados que a avaliaram mais favoravelmente estarem participando de forma mais ativa dos processos de decisão que os afetavam diretamente, razão pela qual estariam se mostrando, também, mais satisfeitos com seu trabalho. 
A Hipótese 4, por fim, previa que as percepções de justiça processual seriam as melhores preditoras dos afetos positivos dirigidos ao trabalho, não foi confirmada, já que as percepções de justiça informacional e interpessoal foram as que tiveram maior impacto nos afetos positivos dirigidos ao trabalho. A hipótese em questão foi formulada em caráter exploratório e com base nas semelhanças conceituais existentes entre a satisfação no trabalho e os afetos positivos dirigidos ao trabalho, na medida em que não foram encontrados estudos anteriores com foco nas relações entre percepções de justiça e afetos positivos dirigidos ao trabalho. Contudo, o fato de as percepções de justiça organizacional terem impactado diferencialmente a satisfação e os afetos no trabalho permite a suposição de que esses fenômenos não são tão similares conceitualmente quanto parecem, havendo assim a necessidade de pesquisas futuras que aprofundem a investigação das reais diferenças ou semelhanças existentes entre eles.

Um resultado não previsto nas hipóteses foi a associação positiva observada entre a idade e a satisfação no trabalho. Foi verificado que, entre os empregados do setor varejista que participaram da pesquisa, aqueles que eram mais velhos mostravam-se mais satisfeitos com o seu trabalho. Embora não tenham sido localizados estudos com foco no comércio varejista de vestuário, a experiência dos autores junto a esse setor tem demonstrado que ele é marcado por grande rotatividade e elevada sobrecarga de trabalho, fatores que costumam gerar estresse e insatisfação nos empregados. Desse modo, é possível supor que aqueles que conseguem desenvolver estratégias mais eficazes de combate a essas situações mostram-se, com o passar do tempo, mais satisfeitos com o trabalho que executam.

\section{CONSIDERAÇÕES FINAIS}

A partir dos anos 90, o comércio varejista sofreu grande impulso, motivado sobretudo pela adoção de novas tecnologias, novos sistemas de gestão e distribuição e de uma cultura voltada prioritariamente à busca de mais clientes. Por outro lado, a competição também aumentou com a entrada de grupos estrangeiros na economia brasileira e com o crescimento das vendas pela internet. Surgem, além disso, as vendas diretas, representadas principalmente por mulheres vendedoras autônomas que conseguem, dessa forma, complementar a renda familiar e conciliar família e trabalho. Apesar desse cenário, as vendas no setor do varejo estão, ainda hoje, concentradas nas lojas, ainda que outros segmentos ganhem espaço (Mattar, 2011).

Esse cenário pode estar impactando a saúde e o bem-estar dos trabalhadores desse setor da economia, o que implica a necessidade de mais investigações voltadas para esse grupo ocupacional que sejam capazes de aprofundar o conhecimento sobre os diferentes fatores associados ao seu bem-estar. Alinhada com essas preocupações, a presente pesquisa buscou verificar o impacto de uma variável específica do contexto do trabalho, as percepções de justiça organizacional, sobre o bem-estar laboral de uma amostra de indivíduos que trabalhavam no setor varejista de vestuário no Estado do Rio de Janeiro.

Tomados em conjunto, os resultados obtidos indicaram que as percepções de justiça organizacional, de maneira geral, impactaram positivamente a satisfação e os afetos positivos que os empregados dirigem ao seu trabalho. Considerando-se, porém, que o setor investigado tem sido marcado por grande sobrecarga de trabalho, o que por vezes impede que os gestores atentem para a prática da justiça no local de trabalho, seria interessante que os profissionais de recursos humanos procurassem dar mais atenção à implementação de tais práticas. Nesse sentido, a adoção de estratégias de gestão pautadas na distribuição de resultados justos, na garantia de participação dos empregados nas tomadas de decisão que lhes dizem respeito e no tratamento cordial por parte dos gestores revestem-se de possibilidades potenciais de contribuir para a melhoria do bemestar dos empregados do comércio varejista de vestuário.

Atendo-se a uma agenda futura de pesquisas, sugere-se a realização de investigações com outras classes de profissionais, assim como de pesquisas qualitativas com profissionais do varejo que sejam capazes de aprofundar os diferentes fatores imbrincados na configuração de seu bem-estar. Vale ressaltar, por fim, as limitações da presente investigação, realizada apenas nas cidades de Niterói, São Gonçalo e Rio de Janeiro, restringindo suas possibilidades de generalização. Ademais, o fato de o grupo pesquisado ser bastante heterogêneo quanto à idade, tempo de trabalho e tempo de serviço pode ter interferido nos resultados, embora essas variáveis tenham entrado como controle na análise de regressão, como forma de amortecer seu impacto.

De todo modo, ela contribuiu para ampliar o escopo das investigações na área do bem-estar dos empregados do setor varejista, na medida em que o levantamento da literatura evidenciou que esta é uma área ainda pouco explorada pelos pesquisadores nacionais e internacionais. Assim, o presente trabalho reveste-se de relevância 
teórica e prática ao fornecer contribuições para a área do comércio varejista e para a literatura no campo da justiça organizacional e do bem-estar no trabalho.

\section{REFERÊNCIAS}

Andrews, M. C., Baker, T. L., \& Hunt, T. G. (2008). The interactive effects of centralization on the relationship between justice and satisfaction. Journal of Leadership \& Organizational Studies, 15, 135-144. doi:10.1177/1548051808320984

Assmar, E. M. L., Ferreira, M. C., \& Souto, S. O. (2005). Justiça organizacional: Uma revisão crítica da literatura. Psicologia: Reflexão e Crítica, 18, 443-453. doi:10.1590/S0102-79722005000300019

Assmar, E. M. L., Ferreira, M. C., Souto, S. O., Souza, A. L. R., Mac-Cord, F., \& Borges, D. (2002). Justiça organizacional: Um modelo multidimensional para uso no Brasil. Anais do I Congresso Brasileiro Psicologia: Ciência e Profissão. Brasília, DF: CFP. Recuperado em 18/06/2012, de http://www.cienciaeprofissao.com.br/congre/downloads.asp

Bies, R. J., \& Moag, J. S. (1986). Interactional justice: Communication criteria of fairness. In R. J. Lewicki, B. H. Sheppard, \& M. H. Bazerman (Eds.). Research on negotiation in organizations (pp. 43-55). Greenwich, CT: JAI Press.

Calvetti, P. U., Muller, M. C., \& Nunes, M. L. T. (2007). Psicologia da saúde e psicologia positiva: perspectivas e desafios. Psicologia: Ciência e Profissão, 27, 706-717. doi:10.1590/S1414-98932007000400011

Clay-Warner, J., Reynolds, J., \& Roman, P. (2005). Organizational justice and job satisfaction: a test of three competing models. Social Justice Research, 18, 391-409. doi:10.1007/s11211-005-8567-5

Colquitt, J. A. (2001). On the dimensionality of organizational justice: a construct validation of a measure. Journal of Applied Psychology, 86, 386-400. doi:10.1037//0021-9010.86.3.386

Cropanzano, R., \& Discorfano, S. M. (2009). Organizational justice. In S. G. Rogelberg (Ed.), Encyclopedia of industrial and organizational psychology (pp. 570-574). Thousand Oaks, CA: Sage Publications.

Cropanzano, R., \& Greenberg, J. (1997). Progress in organizational justice: Tunneling through the maze. In C. L. Cooper, \& I. T. Robertson (Eds.). International review of industrial and organizational psychology (pp. 317-372). New York, NY: Wiley \& Sons.

Ferreira, M. C., Assmar, E. M. L., Souto, S. O., Omar, A. G., Delgado, H. U., González, A. T., \& Galaz, M. M. F. (2006). Individualismo e coletivismo, percepções de justiça e comprometimento em organizações latino-americanas. Interamerican Journal of Psychology, 40, 9-20.

Ferreira, M. C., Silva, A. P., Fernandes, H., \& Pacheco, S. (2008). Desenvolvimento e validação de uma escala de afetos no trabalho. Revista de Avaliação Psicológica, 7, 143-150.

Fields, D., Pang, M., \& Chiu, C. (2000). Distributive and procedural justice as predictors of employee outcomes in Hong Kong. Journal of Organizational Behavior, 21, 547-562. doi:10.1002/1099-1379(200008)21:5<547::AID-JOB41>3.0.CO;2-I

Fiuza, G. D. (2010). Políticas de gestão de pessoas, valores pessoais e justiça organizacional. Revista de Administração Mackenzie, 11, 55-81. doi:10.1590/S1678-69712010000500004

Forgas, J. P. (2001). Affective intelligence: The role of affect in social thinking and behavior. In J. Ciarrochi, J. P. Forgas, \& J. D. Mayer (Eds.). Emotional intelligence and everyday life (pp. 46-63). New York, NY: Psychology Press.

Gilliland, S. W., \& Chan, D. (2001). Justice in organizations: theory, methods, and applications. In N. Anderson, D. S. Ones, H. Sinangil, \& C. Viswesvaran (Eds.). Handbook of industrial, work, and organizational psychology (pp. 143-165). London: Sage Publications.

Gouveia, R. S. V., Lins, Z. M. B., Lima, T. J. S., Freires, L. A., \& Gomes, A. I. A. S. B. (2009). Bem-estar afetivo entre profissionais de saúde. Revista Bioética, 17, 267-280.

Greenberg, J. (1993). The social side of fairness: interpersonal and informational classes of organizational justice. In R. Cropanzano (Ed.). Justice in the workplace: approaching fairness in human resource management (pp. 79-106). Hillsdale, NJ: Lawrence Erlbaum.

Harvey, S., \& Haines III, V. Y. (2005). Employer treatment of employees during a community crisis: the role of procedural and distributive justice. Journal of Business and Psychology, 20, 53-68. doi:10.1007/s10869-005-6983-z

Horta, P., Demo, G., \& Roure, P. (2012). Políticas de gestão de pessoas, confiança e bem-estar: estudo em uma multinacional. Revista de Administração Contemporânea, 16, 566-585. doi:10.1590/S1415-65552012000400005

Instituto Brasileiro de Geografia e Estatística (2014). Indicadores IBGE: Pesquisa mensal de comércio. Brasília: Autor. Recuperado em 12/12/2014, de ftp://ftp.ibge.gov.br/Comercio_e_Servicos/Pesquisa_Mensal_de_Comercio/Fasciculo_ Indicadores_IBGE/pmc_201411caderno.pdf 
Lawson, K. J., Noblet, A. J., \& Rodwell, J. J. (2009). Promoting employee wellbeing: the relevance of work characteristics and organizational justice. Health Promotion International, 24, 223-233.

Locke, E. A. (1976). The nature and causes of job satisfaction. In M. P. Dunnette (Ed.). Handbook of industrial and organizational psychology (pp. 1294-1349). Chicago, IL: Rand-McNally.

Mattar, F. N. (2011). Administração de varejo. Rio de Janeiro: Elsevier-Campus.

Mendonça, H., \& Mendes A. M. (2005). Experiências de injustiça, sofrimento e retaliação no contexto de uma organização pública do estado de Goiás. Psicologia em Estudo, 10, 489-498. doi:10.1590/S1413-73722005000300017

Paludo, S. P., \& Koller, S. H. (2007). Psicologia positiva: Uma nova abordagem para antigas questões. Paidéia, 17, 9-20. doi:10.1590/S0103-863X2007000100002

Paschoal, T., Torres C., \& Porto, J. B. (2010). Felicidade no trabalho: relações com suporte organizacional e suporte social. Revista de Administração Contemporânea, 14, 1054-1072. doi:10.1590/S1415-65552010000700005

Rego, A., \& Souto, S. (2004). A percepção de justiça como antecedente do comprometimento organizacional: um estudo lusobrasileiro. Revista de Administração Contemporânea, 8, 151-177. doi:10.1590/S1415-65552004000100008

Rocha Sobrinho, F., \& Porto, J. B. (2012). Bem-estar no trabalho: um estudo sobre suas relações com clima social, coping e variáveis demográficas. Revista de Administração Contemporânea, 16, 253-270. doi:10.1590/S1415-65552012000200006

Ruviaro, M. F. S., \& Bardagi, M. P. (2010). Síndrome de burnout e satisfação no trabalho em profissionais da área de enfermagem do interior do RS. Barbarói, 33, 194-216.

Silva, A. P. C., \& Ferreira, M. C. (2009). Escala de Satisfação Geral no Trabalho. Anais do IV Congresso Brasileiro de Avaliação Psicológica (p. 246). Campinas, SP: IBAP.

Siqueira, M. M. M., \& Padovam, V. A. R. (2008). Bases teóricas de bem-estar subjetivo, bem-estar psicológico e bem-estar no trabalho. Psicologia: Teoria e Pesquisa, 24, 201-209. doi:10.1590/S0102-37722008000200010

Souza, I. F., \& Mendonça, H. (2009). Burnout em professores universitários: impacto de percepções de justiça e comprometimento afetivo. Psicologia: Teoria e Pesquisa, 23, 499-508. doi:10.1590/S0102-37722009000400005

Spector, P. (1997). Job satisfaction. Thousand Oaks, CA: Sage

Suliman, A. M. T. (2007). Links between justice, satisfaction and performance in the workplace: a survey in the UAE and Arabic context. Journal of Management Development, 26, 294-311. doi:10.1108/02621710710740075

Traldi, M. T. F., \& Demo, G. (2012). Comprometimento, bem-estar e satisfação dos professores de administração de uma universidade federal. Revista Eletrônica de Administração, 18, 290-316.

Tyler, T. R., \& Lind, E. A. (1992). A relational model of authority in groups. In M. Zanna (Ed.). Advances in experimental social psychology (Vol. 25, pp. 115-191). New York, NY: Lexington Books.

Walster, E., Berscheid, E., \& Walster, G. W. (1973). New directions in equity research. Journal of Personality and Social Psychology, 25, 151-176.

Warr, P. B. (1987). Work, unemployment and mental health. Oxford, OH: Claredon Press.

Warr, P. B. (2004). Globalization, growth, and poverty reduction in Thailand. ASEAN Economic Bulletin, 21, 1-18.

Weiss, H. M. (2002). Desconstructing job satisfaction: separating evaluations, beliefs and affective experiences. Human Resource Management Review, 12, 173-194. doi:10.1016/S1053-4822(02)00045-1

Weiss, H. M., \& Cropanzano, R. (1996). Affective events theory: a theoretical discussion of the structure, causes and consequences of affective experiences at work. In B. M. Staw, \& L. L. Cummings (Eds.), Research in organizational behavior (Vol. 19, pp. 1-74).Greenwich, CT: JAI Press. 